\section{Dural MALT lymphoma with disseminated disease}

\author{
Kelly Matmati, Nabil Matmati, \\ Yusuf A. Hannun, Zoran Rumboldt, \\ Sunil Patel, John Lazarchick, \\ Robert Stuart, Pierre Giglio \\ Medical University of South Carolina, \\ Charleston, SC, USA
}

\section{Abstract}

Central nervous system (CNS) lymphoma involving the dura mater is very rare and histologically is usually a subtype of non-Hodgkin's lymphoma (NHL) termed mucosa-associated lymphoid tissue (MALT) lymphoma. We present a case of a 46-year old woman with dural MALT lymphoma that was found to also involve a lacrimal gland, inguinal lymph nodes, and bone marrow. Magnetic resonance imaging of the brain showed an extra-axial enhancing mass approximately $6 \mathrm{~cm}$ in maximum diameter along the right frontotemporal convexity. Histopathology of the resected dural mass showed MALT lymphoma expressing CD20, CD52, CD19, and CD38. Molecular studies of the B-cell receptor heavy chain demonstrated monoclonality at the involved sites. The patient was treated with four cycles of fludarabine, mitoxantrone, and rituximab with complete remission. She had recurrence in the subcutaneous tissue of the back at 12 months but has remained free of intracranial disease for 31 months. A review of the literature reveals 57 cases of dural MALT lymphoma. Only 4 had extra-CNS involvement at presentation, and only 3 had local recurrence of the dural tumor. Because of the indolent behavior of this tumor, the intracranial portion can be treated conservatively after resection with or without chemotherapy. Deferral of brain radiation can be considered with close clinical and neuroimaging follow up.

\section{Introduction}

Central nervous system (CNS) involvement with non-Hodgkin's lymphoma (NHL) falls into one of three categories: primary CNS lymphomas (PCNSL), disseminated lymphoma with CNS involvement, and primary dural lymphoma. Primary CNS lymphomas are typically diffuse large B-cell lymphomas and are found in the brain parenchyma and other CNS structure. ${ }^{1}$ Disseminated lymphoma typically involves the meninges in a leptomeningeal pattern similar to leukemia. ${ }^{2}$ It can also be found intraparenchymally but does not typically occur within the dura. ${ }^{2-4} \mathrm{~A}$ small proportion of CNS lymphomas are extraaxial, intradural lymphomas that typically do not involve the brain parenchyma. ${ }^{5}$ The vast majority of these are low grade extranodal marginal zone lymphomas, also called mucosa-associated lymphoid tissue (MALT) lymphomas (primary dural marginal zone lymphoma, PDMZL), 5,6 although a small number of higher grade lymphomas have been reported including diffuse large B-cell and follicular lymphoma. ${ }^{5}$ Distinguishing among types of CNS lymphoma can be difficult, and the distinction is sometimes obscured in the literature due to lumping of all meningeal lymphomas together. In this review, a dural lymphoma refers to a solid, localized mass, within or indistinguishable from the dura mater, that radiographically may have a dural tail. In contrast, leptomeningeal lymphoma is diffusely spread over the surface of the brain, involving the other meningeal layers but not primarily the dura. When defined in this way, dural lymphoma is relatively rare.

We now report a case of disseminated MALT lymphoma with involvement of the dura and discuss the management of this case in light of the current available literature on such cases.

\section{Case Report}

A 46-year old right handed Caucasian female presented with a small lump in her right upper inner eyelid. This was initially dismissed, but the patient presented again with pressure symptoms in the right frontal region of her head and blurring of vision of the right eye. An MRI of the brain showed a $2 \times 6 \times 6 \mathrm{~cm}$ extra-axial enhancing mass along the right frontal convexity, extending anteriorly to the superior ridge of the orbit. There was no significant edema around the lesion, which was initially felt to be consistent with an en plaque meningioma (Figure 1). On further review, the lesion was found to be extending across the midline with thickening and enhancement of the left frontal dura mater. There was also increased T2 signal in the adjacent cortical sulci with subtle contrast enhancement. The overlying bone marrow also showed abnormal signal, indicative of an infiltrative process. The patient was referred to our institution for a second opinion regarding diagnosis and management. On physical exam she was neurologically intact and positive findings included a small nodule palpable in the right upper palpebra in a supranasal location. She had no palpable lymphadenopathy except shotty inguinal nodes. The dural mass was resected via a right frontal craniotomy. The pathology was consistent with MALT lymphoma expressing CD20, CD52, CD19, and CD38, but not CD5, with
Correspondence: Pierre Giglio, 96 Jonathan Lucas St., Charleston, SC, USA 29425.

E-mail: giglio@musc.edu.

Key words: MALT lymphoma, Dural lymphoma, Radiation, Chemotherapy, Meningioma.

Contributions: RS, SP and PG provided clinical care to the patient and provided data; JL and ZR provided data, analyzed data and contributed to writing and editing the paper; KSM performed the literature review, planned and carried out the experiments, analyzed data, and wrote and edited the paper; NM and YAH contributed to designing the experiments and editing the paper; $\mathrm{PG}$ supervised all aspects of the project and contributed substantially to writing and editing the paper. All authors contributed to editing and approving the final manuscript.

Conflict of interest: the authors report no conflicts of interest.

Received for publication: 15 September 2010.

Revision received: 30 November 2010

Accepted for publication: 1 December 2010.

This work is licensed under a Creative Commons Attribution 3.0 License (by-nc 3.0).

(C) Copyright K. Matmati et al., 2010

Licensee PAGEPress, Italy

Hematology Reports 2010; 2:e10

doi:10.4081/hr.2010.e10

kappa light chain restriction (Figure 2).

A PET-CT scan of the whole body showed shotty cervical, axillary, and inguinal lymph nodes that demonstrated mildly increased metabolic activity -standardized uptake value (SUV) in the 2-4 range with the highest values in inguinal regions. A biopsy of a left inguinal node showed lymphoid proliferation and flow cytometry studies were consistent with a kappa-restricted B-cell neoplastic proliferation. The patient also had an anterior orbitotomy and biopsy of the orbital mass that demonstrated lacrimal gland involvement by MALT lymphoma with the same immunophenotype as the lymph node and the dural mass. Bone marrow biopsy showed a small population (2.6\% of nucleated cells) of kappa-restricted Blymphocytes by flow cytometry, but spinal fluid was negative.

For the tissue taken from the orbit, the dura and the lymph nodes, PCR amplification of the variable region of the B-cell receptor heavy chain (according to published methods, ${ }^{7}$ ) resulted in a single band of about 250 base pairs on gel electrophoresis (Figure 3). PCR of the bone marrow failed to yield a defined single band. The PCR products were sent for sequencing, and sequence analysis indicated that the sequences from the orbit and the dura 

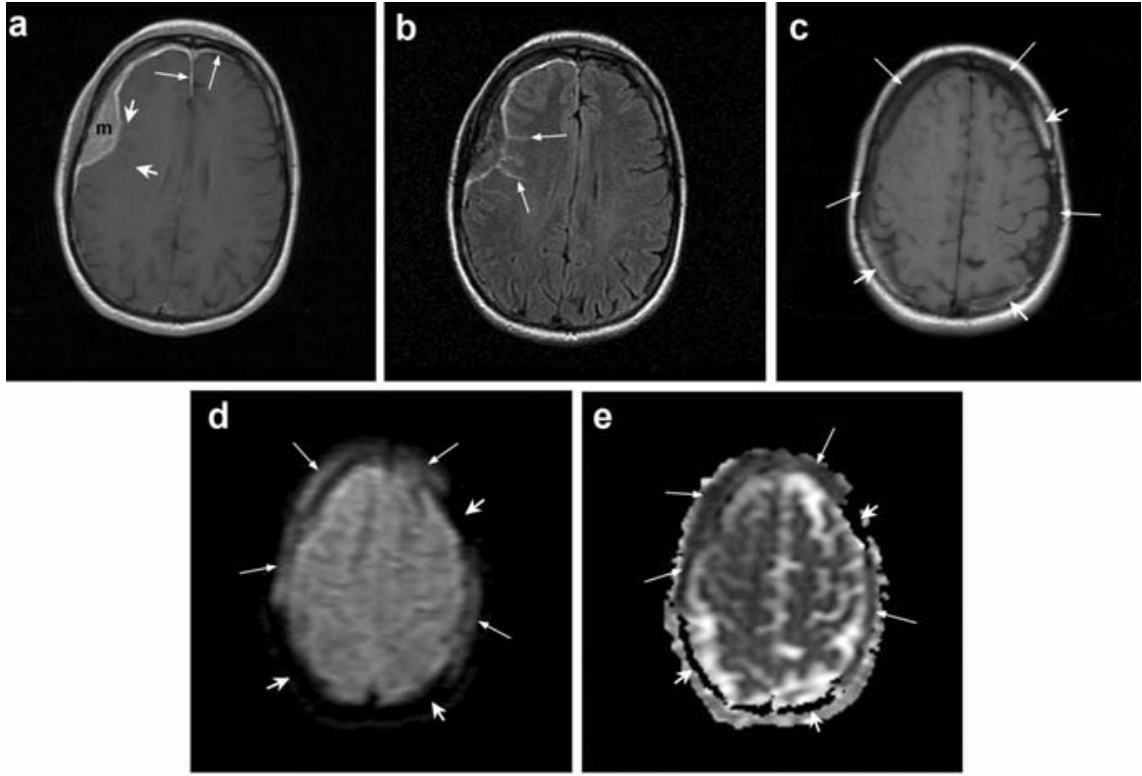

Figure 1. Brain MR imaging. (a) Post-contrast axial T1-weighted image shows a homogenously enhancing extra-axial dural-based mass $(\mathrm{m})$ in the right frontal region. The thickening and enhancement of the dura extends anteriorly along the falx and along the left frontal lobe (long arrows). There is also subtle enhancement extending into a few of the adjacent cortical sulci (short arrows). (b) Corresponding axial fluid-attenuated inversion recovery (FLAIR) image reveals abnormal hyperintensity within the cortical sulci (arrows) adjacent to the lesion, corresponding to subtle enhancement in A). (c) Non-enhanced axial T1weighted image at a slightly higher level demonstrates loss of normal bone marrow hyperintensity in the calvarium adjacent to the dural mass and in the left parietal bone (long arrows). Note normal bright bone marrow (short arrows). (d) Corresponding diffusionweighted image (DWI) reveals signal intensity similar to the dural mass within the affected bone marrow (long arrows). Note normal bone marrow without any signal (short arrows). (e) Corresponding apparent diffusion coefficient (ADC) map shows that the diffusion of water molecules within the affected bone marrow is similar to the dural lesion (long arrows). Normal bone marrow remains black without any signal (short arrows).

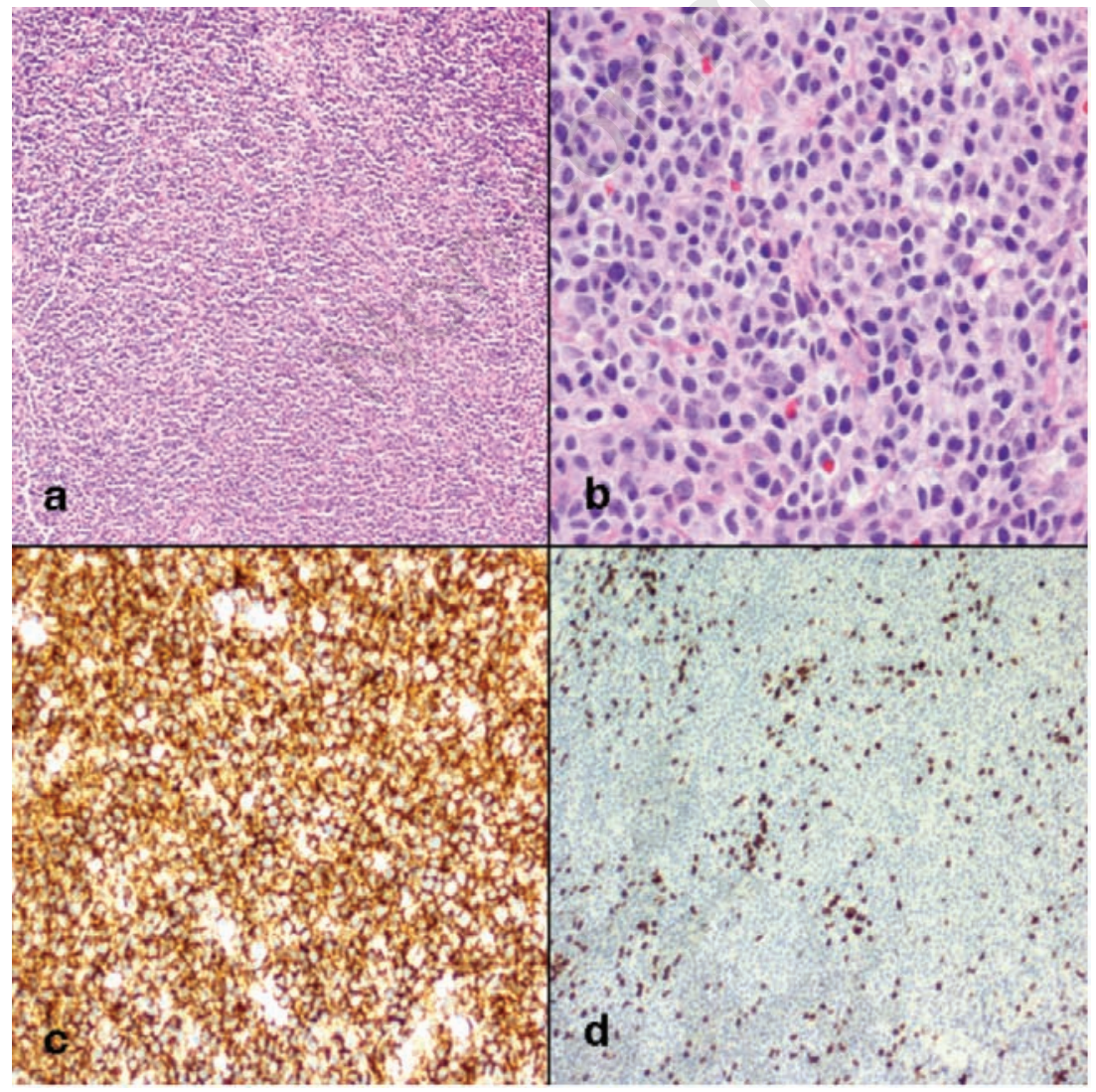

had $99.2 \%$ identity. The sequence from the lymph nodes was of lesser quality, but also had a very high identity with the dural sequence (80.1\%), indicating that the lymphoid cells in these tissues were clonally related.

The patient was treated with intravenous fludarabine, mitoxantrone, and rituximab every four weeks for a total of four cycles. The patient did not receive radiation treatment to the dural lesion; the decision was made to follow her closely with serial MRIs to monitor for intracranial recurrence.

The patient relapsed with biopsy-proven MALT lymphoma in subcutaneous tissues of the back and buttock 12 months after diagnosis. A bone marrow biopsy at that time was negative for malignancy. She was treated with additional rituximab and then maintained on rituximab. At 33 months since diagnosis she is again in complete remission and has remained free of CNS disease.

\section{Materials and Methods}

Several thick slices of paraffin embedded tissue were provided by the pathology laboratory. Genomic DNA was extracted using the Qiagen DNeasy Blood \& Tissue kit. Semi-nested PCR was performed as previously described $^{7,8}$ using the following degenerate primers:

FR2a: TGG(A/G)TCCG(C/A)CAG(G/C)C(T/C) (T/C)CNGG

\section{LJH: TGAGGAGACGGTGACC}

\section{VLJH: GTGACCAGGGTNCCTTGGCCCCAG}

Primers were ordered from Integrated DNA Technologies (IDT ${ }^{\circledR}$ ). PCR conditions were as follows: denaturation at $94^{\circ} \mathrm{C}$ for $5 \mathrm{~min}$, followed by 40 cycles of $94^{\circ} \mathrm{C}$ for $2 \mathrm{~min}, 50^{\circ} \mathrm{C}$ for

Figure 2. Morphology and immunohistochemical staining of dural mucosa-associated lymphoid tissue (MALT lymphoma) (a) At low magnification there is a diffuse lymphocytic infiltration of the dura with characteristic perivascular pattern. Follicular structures were not identified. (original magnification x100). (b) At higher magnification the neoplastic cells can be seen to exhibit a morphologic spectrum with abundant pale agranular cytoplasm and small to medium-sized nuclei with round to irregular nuclear borders. Rare large centroblast-like cells and plasma cells are present (original magnification $\times 400$ ). (c) CD20 immunohistochemical stain shows diffuse positivity (original magnification x50). (d) CD3 immunohistochemical stain shows only scattered positive cells (original magnification $\mathbf{x} 50$ ). 
$2 \mathrm{~min}$, and $72^{\circ} \mathrm{C}$ for $2 \mathrm{~min}$, followed by elongation at $72^{\circ} \mathrm{C}$ for $20 \mathrm{~min}$. Genomic DNA was first amplified with the FR2a and LJH primers, then a 1:5000 dilution of the PCR product was amplified with the FR2a and VLJH primers. Products were analyzed by electrophoresis on a $2 \%$ agarose gel and then extracted using Qiaquick Gel Extraction Kit ${ }^{\circledR}$. PCR products were sent for sequencing at the MUSC Biotechnology Resource Laboratory. Some sequences were corrected by visually calling nucleotides from the chromatogram using ChromasLite 2.01 from Technelysium Pty Ltd. ${ }^{\odot}$ (http://www.technelysium.com.au). Sequences were analyzed using Biology Workbench 3.2 (http://seqtool.sdsc.edu).

\section{Discussion}

This report describes a patient with disseminated low grade MALT lymphoma that involved the dura. The histological evidence showed that a B-cell malignancy was disseminated at presentation, involving the lacrimal gland, lymph nodes, bone marrow and intracranial dura. Examination of all of these tissues revealed a MALT lymphoma. This tissue distribution suggests that the patient had a subclinical MALT lymphoma that became disseminated. Laboratory studies proved that the lymphoid proliferations were neoplastic and not reactive or inflammatory processes. PCR amplification of the IGH variable region in the samples from dura, lymph node and lacrimal gland demonstrated a single band of the same size, indicating monoclonality. In addition, sequencing of this segment demonstrated fur-

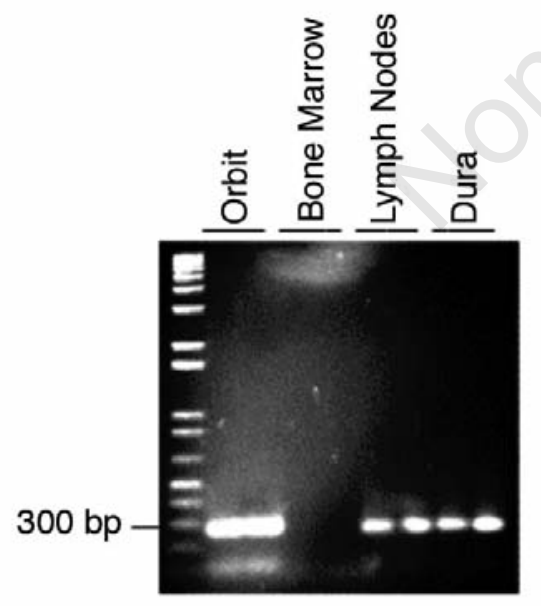

Figure 3. PCR amplification of the variable region of the $B$-cell receptor heavy chain resulted in a single band for tissue taken from the orbit, lymph node and dura, demonstrating that rearrangement has occurred and the B-cells are monoclonal. PCR of the bone marrow failed to yield a defined single band. ther that the gene rearrangement was identical in this region.

Dural lymphomas pose special diagnostic and therapeutic challenges. Because they are uncommon, they are often initially misdiagnosed as meningiomas or other lesions based on imaging. ${ }^{3,-42}$ Intracranial lymphomas may be epidural, dural, subdural, subarachnoid, and combinations of these. ${ }^{43} \mathrm{~A}$ dural mass with associated leptomeningeal and/or bone marrow imaging abnormalities is highly unusual for meningioma and is suggestive of lymphoma or metastatic malignancy. Since the therapy for meningioma and dural lymphoma are different, several authors have stressed the importance of getting a tissue diagnosis before treatment of a dural lesion identified on MRI. ${ }^{15,31,33,44}$

The majority of dural lymphomas are MALT lymphomas. ${ }^{5}$ MALT lymphoma is a type of Bcell lymphoma that has the characteristics of marginal zone cells and typically arises from nests of lymphoid cells in mucosal tissues. Occasionally it is found to arise in non-mucosal sites such as skin, orbit or dura. ${ }^{45,46}$ MALT lymphoma was originally described by Isaacson and Wright in $1983 .{ }^{47}$ Since that time, clinical experience with this entity has steadily grown, as has the understanding of its etiology and pathogenesis. According to the Revised European - American Classification of Lymphoid Neoplasms (REAL) and the subsequent update by the World Health Organization (WHO), Classification of Neoplasms of the Hematopoietic and Lymphoid Tissues, marginal zone B-cell lymphomas are a histologic category of the mature peripheral B-cell neoplasms. ${ }^{48,49}$ Marginal zone B-cell lymphomas (MZLs) are further divided clinically into nodal, extranodal, and splenic types. Extranodal marginal zone B-cell lymphoma is equivalent to MALT lymphoma. While the earlier REAL classification considered extranodal and nodal MZLs to be histologically the same, only distinguishable by their clinical presentation, the newer WHO classification regards nodal MZLs to be a distinct entity with a worse prognosis than extranoda//MALT MZLs with nodal involvement. ${ }^{48,49}$ MALT lymphomas usually arise in the gastrointestinal tract, especially the stomach, but are also found in the head and neck region (orbital tissues, salivary glands, and thyroid), skin, and lung.

MALT lymphoma generally has a good prognosis and can be treated with minimally toxic methods. ${ }^{5,50,51}$ While MALT lymphoma usually remains localized for a long time, retrospective studies have shown that one third to one fourth of non-gastrointestinal cases had disseminated disease at diagnosis. ${ }^{46,50,51}$ One report indicates that MALT lymphomas arising in non-gastrointestinal tract locations have a higher rate of dissemination that those arising in the GI tract. ${ }^{52}$ MALT lymphomas have a ten- dency to spread to non-contiguous mucosa associated sites. ${ }^{52}$ Whether disseminated MALT lymphoma carries a poorer prognosis than localized disease is a subject of debate. In a series of patients studied by Arcaini et al.,45 dissemination to lymph nodes or bone marrow was associated with shorter overall survival, while Thieblemont et al. found no difference in outcome between patients with disseminated versus localized disease. ${ }^{51,53}$

While MALT lymphomas remain indolent, there is a risk of transformation to higher grade lymphomas. In most cases, MALT lymphomas have been reported to transform into diffuse large B-cell lymphoma, ${ }^{54-57}$ which has a much worse prognosis. Indolent lymphomas transform into higher grade lymphomas at a rate of $3 \%$ per year. ${ }^{58}$

No evidence based guidelines exist for treating MALT and the other types of marginal zone lymphoma, but current treatment strategies have been reviewed by Thieblemont and Coiffier. ${ }^{45}$ Localized disease that is clearly linked to an infectious stimulus (such as Helicobactor pylori in gastric MALT lymphoma) has been treated with antibiotics as the sole initial treatment, resulting in complete remission, although it is uncertain if this completely eradicates neoplastic cells. For localized MALT that is not linked to an infectious stimulus, localized treatment with surgery or radiation has been successful. For disseminated disease, a number of chemotherapeutic agents have been tried, including corticosteroids, alkylating agents (cyclophosphamide and chlorambucil), nucleoside analogues (fludarabine and cladribine), doxorubicin, mitoxantrone, and rituximab, alone or in combination. . $^{45,59-61}$

The clinician encountering a patient with dural MALT lymphoma has little guidance on what therapies might be effective in controlling the disease and if, in fact, radiation or cytotoxic treatment is warranted after resection, given the indolent nature of the disease and the potential for CNS toxicity. Radiation has been considered a preferred therapy for localized dural MALT lymphoma because it is a very radiosensitive tumor, and a local modality of treatment is appropriate for a tumor that generally remains localized. However, there is no consensus on dose and schedule, and irradiation of the brain has significant side effects and must be used judiciously, especially in young to middle aged patients who are at increased risk of early dementia. In the case of a dural MALT lymphoma that is not localized, radiation may be less preferred because the patient must receive systemic therapy for the disseminated disease and additional therapy may not be necessary.

An interesting feature of the lymphoma in this case is the unusual tissue distribution. As described above, MALT lymphoma is usually indolent and rarely becomes disseminated. 
Table 1. Dural based lymphoma in the literature by histological type (see text for references).

\begin{tabular}{lcc} 
Histology & $\begin{array}{c}\text { Number } \\
\text { of cases }\end{array}$ & $\begin{array}{c}\text { Extra-CNS } \\
\text { involvement } \\
\text { presentation }\end{array}$ \\
$\begin{array}{l}\text { MALT/Marginal } \\
\text { zone lymphoma }\end{array}$ & 67 & 4 \\
$\begin{array}{l}\text { Diffuse large } \\
\text { B-cell lymphoma }\end{array}$ & 9 & 1 \\
\hline $\begin{array}{l}\text { Follicular lymphoma } \\
\text { CLL/SLL }\end{array}$ & 6 & 4 \\
\hline Other & 6 & 0 \\
Total & 5 & 1 \\
\hline
\end{tabular}

Dural MALT lymphoma is almost always localized, without systemic involvement. Only 4 cases have been reported with involvement outside of the CNS on presentation; ${ }^{10,35,62}$ this case is the fifth. In two of these cases, the only extra-CNS involvement was in the ocular adnexa, with presumed contiguous spread to the globe, the optic nerve, cavernous sinus and the dura. ${ }^{10}$

Dural lymphoma is relatively rare, and most of the reported cases are of dural MALT, the most common type. Here we attempt to summarize the available literature on dural lymphoma. A literature search found 93 cases of dural based lymphomas (Table 1). Of these, 67 (72\%) were described as MALT or marginal zone lymphoma, ${ }^{6,9,10,12,15,16,20-25,28-35,41,44,62-70} 9$ were diffuse large B-cell lymphoma, ${ }^{11,14,18,27,36,37,42,71}$ and 6 were follicular lymphoma., ${ }^{3,17,26,38,40,72} \mathrm{Six}$ were described as small lymphocytic lymphoma $^{13,14,73,74}$ or B-cell lymphoproliferative disorder of CLL type ${ }^{75}$ but the four of these that were described prior to the establishment of the REAL-WHO criteria may have actually been MALT/Marginal zone lymphoma since immunophenotypical analysis was not performed. ${ }^{15,74}$ The remaining 5 cases were described in various ways, including large-cell immunoblastic T-cell lymphoma, ${ }^{14}$ monocytoid malignant B-cell lymphoma, ${ }^{76}$ centroblastic/ centrocytic lymphoma, ${ }^{19}$ precursor B-cell lymphoblastic lymphoma, ${ }^{77}$ and diffuse large cell non-Hodgkin lymphoma due to Richter's transformation. ${ }^{39}$ Of the cases of dural MALT lymphoma/MZL, 63 (94\%) were isolated to the CNS, while only 4 (6\%) were associated with extra-CNS disease at the time of diagnosis. An additional 5 cases subsequently became disseminated. Of the non-MALT dural lymphomas, $20(77 \%)$ were isolated to the dura, and 6 (23\%) were associated with disseminated disease. While these numbers are small, they suggest that dural MALT lymphomas are highly likely to remain as primary dural tumors and not spread to other tissues. Other dural lymphomas appear to have a higher incidence of either arising in the context of a disseminated

Table 2. Outcomes of dural MALT lymphoma cases in the literature by treatment modality (see text for references).

\begin{tabular}{lccc}
$\begin{array}{l}\text { Treatment post } \\
\text { surgery/biopsy }\end{array}$ & $\begin{array}{c}\text { Number of cases } \\
\text { \# with outcomes } \\
\text { reported) }\end{array}$ & $\begin{array}{c}\text { Local } \\
\text { recurrence }\end{array}$ & $\begin{array}{c}\text { Systemic } \\
\text { recurrence }\end{array}$ \\
Chemotherapy only & $5(4)$ & 2 & 0 \\
Radiation only & $30(30)$ & 0 & 2 \\
\hline Radiation + chemo & $18(17)$ & 1 & 4 \\
None & $5(4)$ & 0 & 0 \\
\hline Unknown & $9(2)$ & 0 & 0 \\
\hline
\end{tabular}

lymphoma, or arising in the dura and subsequently disseminating.

Of the 57 cases of dural MALT lymphoma that have outcomes reported after partial or total surgical resection, only 3 had local recurrence in the dura, and only 6 had systemic recurrence (Table 2). Of those receiving radiation, 1 out of 47 had local recurrence. Of those receiving chemotherapy, 3 out of 21 had local recurrence (17 patients received both chemotherapy and radiation). Of those receiving chemotherapy alone, 2 out of 4 had local recurrence. None of the 4 patients who received neither chemotherapy nor radiation had local or systemic recurrence. Follow-up was highly variable, but average progression free survival for dural MALT lymphoma was greater than 29 months. Of the four patients who had extra-CNS disease at presentation, 1 received chemotherapy only, 1 received radiation only and the other two received radiation and chemotherapy.

These numbers, while small, suggest that local recurrence is uniformly rare after surgical resection. Local recurrence occurred slightly more frequently with chemotherapy alone than with radiation alone, however the significance of this is unclear since there were only 3 instances of local recurrence in the entire series. In two of the three cases of local recurrence, the patients were salvaged with additional chemotherapy with complete response. ${ }^{10,31}$ Puri et al. propose involved field radiation (IFRT) as an effective means to locally control dural MALT lymphoma, however it is unclear whether even the reduced toxicity of IFRT is justified in a disease that so rarely has local recurrence. ${ }^{6}$ In the current case, the patient received systemic chemotherapy for her disseminated disease, which may have also served to control her dural tumor since the dura is not protected by the blood-brain barrier. Based on the published experience, the clinician encountering a dural MALT lymphoma, with or without dissemination, must carefully weigh the need for radiotherapy, but may consider deferring radiotherapy, with close follow- up. This is especially true in the setting of complete resection or systemic chemotherapy.

\section{Conclusions}

This case of disseminated MALT lymphoma with involvement of the dura demonstrates the importance of maintaining a wide differential diagnosis for dural lesions with imaging characteristics that appear typical for a meningioma. Careful analysis of the imaging studies, primarily MRI, frequently offers additional information, detecting the imaging findings that are suggestive of other disease processes, such as lymphoma. A biopsy and tissue diagnosis should be obtained and complete staging should be done. Dural MALT lymphomas appear to have a very low incidence of local recurrence and therefore irradiation may not be necessary; close surveillance is a valid option for managing this indolent tumor.

\section{References}

1. Commins DL. Pathology of primary central nervous system lymphoma. Neurosurg Focus 2006;21:E2.

2. Gleissner B, Chamberlain M. Treatment of CNS dissemination in systemic lymphoma. J Neurooncol 2007;84:107-17.

3. Low I, Allen J. Low-grade follicular lymphoma in the dura: rare mimic of meningioma. Neuropathology 2006;26:564-8.

4. Bierman P, Giglio P. Diagnosis and treatment of central nervous system involvement in non-Hodgkin's lymphoma. Hematol Oncol Clin North Am;19:597-609.

5. Iwamoto FM, Abrey LE. Primary dural lymphomas: a review. Neurosurg Focus 2006;21:E5.

6. Puri DR, Tereffe W, Yahalom J. Low-dose and limited-volume radiotherapy alone for primary dural marginal zone lymphoma: 
treatment approach and review of published data. Int $\mathrm{J}$ Radiat Oncol Biol Phys 2008;71:1425-35.

7. Uchiyama M, Maesawa C, Yashima A, et al. Consensus primers for detecting monoclonal immunoglobulin heavy chain rearrangement in B cell lymphomas. J Clin Pathol 2003;56:778-9.

8. Ramasamy I, Brisco M, Morley A. Improved PCR method for detecting monoclonal immunoglobulin heavy chain rearrangement in B cell neoplasms. J Clin Pathol 1992;45:770-5.

9. Gocmen S, Gamsizkan M, Onguru 0, et al. Primary dural lymphoma mimicking a subdural hematoma. J Clin Neurosci 2010;17: 380-2.

10. Bayraktar S, Stefanovic A, Montague N, et al. Central nervous system manifestations of marginal zone B-cell lymphoma. Ann Hematol 2010;89:1003-9.

11. Ochiai H, Kawano H, Miyaoka R, et al. Primary diffuse large B-cell lymphomas of the temporoparietal dura mater and scalp without intervening skull bone invasion. Neurol Med Chir (Tokyo). 2010;50:595-8.

12. Shaia J, Kerr PB, Saini A, et al. Mucosaassociated lymphoma tissue of the dura presenting as meningioma. South Med J 2010;103:950-2.

13. Nguyen D, Nathwani BN. Primary meningeal small lymphocytic lymphoma. Am J Surg Pathol 1989;13:67-70.

14. Miranda RN, Glantz LK, Myint MA, et al. Stage IE non-Hodgkin's lymphoma involving the dura: A clinicopathologic study of five cases. Arch Pathol Lab Med 1996; 120:254-60

15. Kumar S, Kumar D, Kaldjian EP, et al. Primary low-grade B-cell lymphoma of the dura: a mucosa associated lymphoid tissue-type lymphoma. Am J Surg Pathol 1997;21:81-7.

16. Kambham N, Chang Y, Matsushima AY. Primary low-grade B-cell lymphoma of mucosa-associated lymphoid tissue (MALT) arising in dura. Clin Neuropathol. 1998;17:311-7.

17. Hodgson D, David KM, Powell M, Holton JL, Pezzella F. Intracranial extracerebral follicular lymphoma mimicking a sphenoid wing meningioma. J Neurol Neurosurg Psychiatry 1999;67:251-2.

18. Amaker BH, Ghatak NR, Jebraili SA, et al. Primary T-cell-rich B-cell lymphoma masquerading as a meningioma. Arch Pathol Lab Med 2000;124:1700-3.

19. Freudenstein D, Bornemann A, Ernemann $\mathrm{U}$, et al. Intracranial malignant B-cell lymphoma of the dura. Clin Neuropathol 2000;19:34-7.

20. Sanjeevi A, Krishnan J, Bailey PR, Catlett J. Extranodal marginal zone B-cell lymphoma of malt type involving the cav- ernous sinus. Leuk Lymphoma. 2001;42:1133-7.

21. Lehman NL, Horoupian DS, Warnke RA, et al. Dural marginal zone lymphoma with massive amyloid deposition: rare lowgrade primary central nervous system Bcell lymphoma. Case report. J Neurosurg 2002;96:368-72.

22. Lima VS, Leite EB, Fonseca RP, Fernandes AS, Jr. Patients presenting with CNS lesions. Case 1. Primary low-grade mucosa-associated B-cell lymphoma of the dura. J Clin Oncol 2003;21:4058-60.

23. Vazquez A, Portillo E, Guridi J, et al. [Primary low-grade non-Hodgkin's B lymphoma mimicking meningioma]. Neurocirugia (Astur) 2002;13:50-3.

24. Bodi I, Hussain A, Gullan RW, Safa AS. January 2003: 56-year-old female with right frontal tumor of the dura. Brain Pathol 2003;13:417-8, 23.

25. Benouaich A, Delord JP, Danjou M, et al. [Primary dural lymphoma: a report of two cases with review of the literature]. Rev Neurol (Paris) 2003;159:652-8.

26. Beriwal S, Hou JS, Miyamoto C, GarciaYoung JA. Primary dural low grade BCL-2 negative follicular lymphoma: a case report. J Neurooncol 2003;61:23-5.

27. Roonprapunt $\mathrm{C}$, Ratech $\mathrm{H}$, LaSala $\mathrm{P}$, et al. Primary diffuse B-cell lymphoma arising in the dura in an immunocompetent individual: case report (Abstract 146). J Neuropathol Exp Neurol 2003;62:574.

28. Raso P, Monteiro ER, Tafuri A. [Primary low grade B-cell lymphoma MALT type of the duramater: case report]. Arq Neuropsiquiatr 2004;62:173-6.

29. Rottnek M, Strauchen J, Moore F, Morgello S. Primary dural mucosa-associated lymphoid tissue-type lymphoma: case report and review of the literature. J Neurooncol 2004;68:19-23.

30. Goetz P, Lafuente J, Revesz T, et al. Primary low-grade B-cell lymphoma of mucosa-associated lymphoid tissue of the dura mimicking the presentation of an acute subdural hematoma. Case report and review of the literature. J Neurosurg 2002;96:611-4.

31. Tu PH, Giannini C, Judkins AR, et al. Clinicopathologic and genetic profile of intracranial marginal zone lymphoma: a primary low-grade CNS lymphoma that mimics meningioma. J Clin Oncol 2005;23:5718-27.

32. Assaf C, Coupland SE, Hummel M, Jahnke K, Mostafafivar S, Stein H, et al. Relapse of primary extranodal marginal-zone B-cell lymphoma of the dura mater. Lancet Oncol 2005;6:187-9.

33. Menniti A, Moschettoni L, Liccardo G, et al. Low-grade primary meningeal lymphoma: case report and review of the literature.
Neurosurg Rev 2005;28:229-33.

34. Saggioro FP, Colli BO, Paixao-Becker AN, et al. Primary low-grade MALT lymphoma of the dura. Histopathology 2006;49:323-6.

35. Pavlou G, Pal D, Bucur S, et al. Intracranial non-Hodgkin's MALT lymphoma mimicking a large convexity meningioma. Acta Neurochir (Wien) 2006;148:791-3.

36. Galarza M, Gazzeri R, Elfeky HA, Johnson RR, 2nd. Primary diffuse large B-cell lymphoma of the dura mater and cranial vault. Case report and literature review. Neurosurg Focus 2006;21:E10.

37. Yamada SM, Ikawa N, Toyonaga S, et al. Primary malignant B-cell-type dural lymphoma: Case report. Surg Neurol 2006;66: 539-43.

38. Hamilton DK, Bourne TD, Ahmed H, et al. Follicular lymphoma of the dura: case report. Neurosurgery 2006;59:E703-4.

39. Ghofrani M, Tantiwongkosi B, Smith AS, Wasdahl DA. Richter transformation of chronic lymphocytic leukemia presenting as a dural-based non-hodgkin lymphoma mass. AJNR Am J Neuroradiol 2007;28:318-20.

40. Riccioni L, Morigi F, Cremonini AM. Follicular lymphoma of the dura associated with meningioma: a case report and review of the literature. Neuropathology 2007;27:278-83.

41. Ancheta RG, Lewin H, Said J, Hurvitz SA. Primary dural marginal zone lymphoma in a woman with inflammatory breast cancer. J Clin Oncol 2008;26:326-8.

42. Sacho RH, Kogels M, du Plessis D, et al. Primary diffuse large B-cell central nervous system lymphoma presenting as an acute space-occupying subdural mass. J Neurosurg. 2010;113:384-7.

43. Smirniotopoulos JG, Murphy FM, Rushing EJ, et al. Patterns of contrast enhancement in the brain and meninges. Radiographics 2007;27:525-51.

44. George AC, Ozsahin M, Janzer R, et al. Primary intracranial dural lymphoma of mucosa-associated lymphoid tissue (MALT) type: report of one case and review of the literature. Bull Cancer 2005;92:E516.

45. Thieblemont C, Coiffier B. Management of marginal zone lymphomas. Curr Treat Options Oncol 2006;7:213-22.

46. Bertoni F, Zucca E. State-of-the-art therapeutics: marginal-zone lymphoma. J Clin Oncol 2005;23:6415-20.

47. Isaacson P, Wright DH. Malignant lymphoma of mucosa-associated lymphoid tissue. A distinctive type of B-cell lymphoma. Cancer 1983;52:1410-6.

48. Harris NL, Jaffe ES, Diebold J, et al. The World Health Organization classification of neoplasms of the hematopoietic and lymphoid tissues: report of the Clinical 
Advisory Committee meeting--Airlie House, Virginia, November,1997 Hematol J 2000;1:53-66.

49. Harris NL, Jaffe ES, Stein H, et al. A revised European-American classification of lymphoid neoplasms: a proposal from the International Lymphoma Study Group. Blood 1994;84:1361-92.

50. Zucca E, Conconi A, Pedrinis E, et al. Nongastric marginal zone B-cell lymphoma of mucosa-associated lymphoid tissue. Blood 2003;101:2489-95.

51. Thieblemont C, Berger F, Dumontet C, et al. Mucosa-associated lymphoid tissue lymphoma is a disseminated disease in one third of 158 patients analyzed. Blood. 2000 Feb 1;95(3):802-6.

52. Thieblemont $\mathrm{C}$, de la Fouchardiere A, Coiffier B. Nongastric mucosa-associated lymphoid tissue lymphomas. Clin Lymphoma 2003;3:212-24.

53. Arcaini L, Burcheri S, Rossi A, et al. Nongastric marginal-zone B-cell MALT lymphoma: prognostic value of disease dissemination. Oncologist 2006;11:285-91.

54. Ghesquieres H, Berger F, Felman P, et al. Clinicopathologic characteristics and outcome of diffuse large B-cell lymphomas presenting with an associated low-grade component at diagnosis. J Clin Oncol 2006;24:5234-41.

55. Koyama R, Hirayama Y, Nagai T, et al. A case of diffuse large B-cell lymphoma transformed from immunoglobulin A-producing marginal zone B-cell lymphoma. Int J Hematol 2000;72:349-52.

56. Hosing C, Freedman RS, McLaughlin P, et al. Diffuse large B-cell non-Hodgkin's lymphoma presenting as a vaginal mass in a patient with a history of intestinal mucosa-associated lymphoid tissue (MALT) lymphoma. Am J Clin Oncol 2001; 24:204-8.

57. Sagaert X, de Paepe P, Libbrecht L, et al. Forkhead box protein P1 expression in mucosa-associated lymphoid tissue lymphomas predicts poor prognosis and trans- formation to diffuse large B-cell lymphoma. J Clin Oncol 2006;24:2490-7.

58. Freedman AS. Biology and management of histologic transformation of indolent lymphoma. Hematology Am Soc Hematol Educ Program 2005:314-20.

59. Wohrer S, Drach J, Hejna M, et al. Treatment of extranodal marginal zone Bcell lymphoma of mucosa-associated lymphoid tissue (MALT lymphoma) with mitoxantrone, chlorambucil and prednisone (MCP). Ann Oncol 2003;14:175861.

60. Jager G, Neumeister P, Brezinschek R, et al. Treatment of extranodal marginal zone B-cell lymphoma of mucosa-associated lymphoid tissue type with cladribine: a phase II study. J Clin Oncol 2002;20:38727.

61. Raderer M, Jager G, Brugger S, et al. Rituximab for treatment of advanced extranodal marginal zone B cell lymphoma of the mucosa-associated lymphoid tissue lymphoma. Oncology 2003;65:306-10.

62. Wedgwood A, Medeiros LJ, Romaguera JE. CD20+ nodal marginal zone B-cell lymphoma with CD20-recurrence as an intracranial dural-based mass. Leuk Lymphoma 2006;47:2253-6.

63. Altundag MK, Ozisik Y, Yalcin S, et al. Primary low grade B-cell lymphoma of the dura in an immunocompetent patient. $\mathrm{J}$ Exp Clin Cancer Res 2000;19:249-51.

64. Itoh T, Shimizu M, Kitami K, et al. Primary extranodal marginal zone B-cell lymphoma of the mucosa-associated lymphoid tissue type in the CNS. Neuropathology 2001;21:174-80.

65. Estevez M, Chu C, Pless M. Small B-cell lymphoma presenting as diffuse dural thickening with cranial neuropathies. J Neurooncol 2002;59:243-7.

66. Azua-Romeo J, Alfaro Torres J, Rivero D, Sanchez Marin B. [Primary MALT lymphoma arising in dura in a 33 years old woman]. Med Clin (Barc) 2003;121:797-8.

67. Iwamoto FM, DeAngelis LM, Abrey LE.
Primary dural lymphomas: a clinicopathologic study of treatment and outcome in eight patients. Neurology 2006;66:1763-5.

68. Bhagavathi S, Greiner TC, Kazmi SA, et al. Extranodal marginal zone lymphoma of the dura mater with IgH/MALT1 translocation and review of literature. $\mathrm{J}$ Hematop 2008;1:131-7.

69. Razaq W, Goel A, Amin A, Grossbard ML. Primary central nervous system mucosaassociated lymphoid tissue lymphoma: case report and literature review. Clin Lymphoma Myeloma 2009;9:E5-9.

70. Ferguson SD, Musleh W, Gurbuxani S, et al. Intracranial mucosa-associated lymphoid tissue (MALT) lymphoma. J Clin Neurosci 2010;17:666-9.

71. Macnealy MW, Newton HB, McGregor JM, et al. Primary meningeal CNS lymphoma treated with intra-arterial chemotherapy and blood-brain barrier disruption. $\mathrm{J}$ Neurooncol 2008;90:329-33.

72. Peltier J, Fichten A, Lefranc M, et al. [Follicular dural lymphoma. Case report]. Neurochirurgie 2009;55:345-9.

73. Jazy FK, Shehata WM, Tew JM, et al. Primary intracranial lymphoma of the dura. Arch Neurol 1980;37:528-9.

74. Giordano A, Perrone T, Guarini A, et al. Primary intracranial dural B cell small lymphocytic lymphoma. Leuk Lymphoma 2007;48:1437-43.

75. Kiewe P, Dallenbach FE, Fischer L, et al. Isolated B-cell lymphoproliferative disorder at the dura mater with B-cell chronic lymphocytic leukemia immunophenotype. Clin Lymphoma Myeloma 2007;7:594-6.

76. Abdel Aziz KM, van Loveren HR. Primary lymphoma of Meckel's cave mimicking trigeminal schwannoma: case report. Neurosurgery 1999;44:859-62.

77. Abdullah S, Morgensztern D, Rosado MF, Lossos IS. Primary lymphoblastic B-cell lymphoma of the cranial dura mater: a case report and review of the literature. Leuk Lymphoma 2005;46:1651-7. 